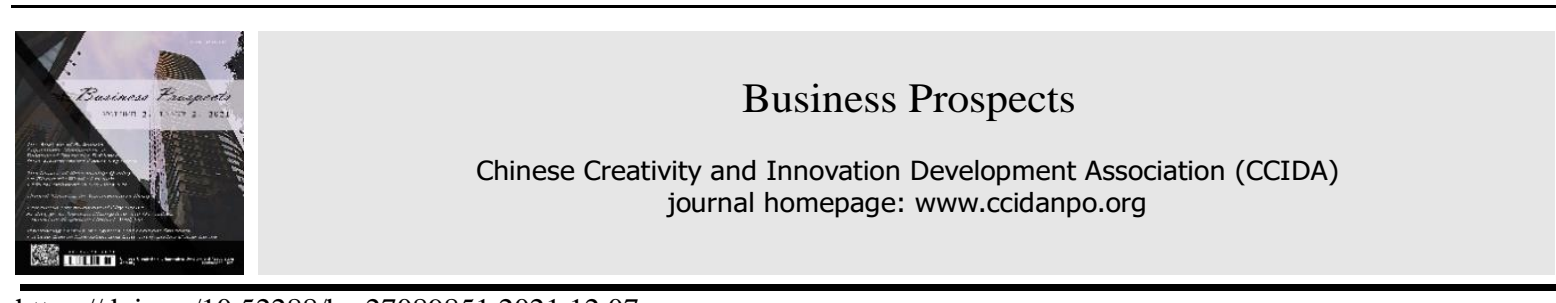

https://doi.org/10.52288/bp.27089851.2021.12.07

\title{
Analysis and Research on E-commerce Live Broadcast Sales Model from the Perspective of Supply Chain
}

\author{
Gong-Jian Zhou ${ }^{1, *}$ \\ ${ }^{1}$ Associate Professor of School of Management, Xiamen University Tan Kah Kee College \\ * Correspondence: 63223748@qq.com
}

Received: 2021.07.03; Accepted: 2021.10.01; Published: 2021.12.01

\begin{abstract}
The e-commerce live broadcast sales model is a brand-new sales model born based on web live broadcasts, and it has quickly been favored by the consumer goods market. As a new sales format, we need to conduct an in-depth analysis of its model to grasp the law of its generation and development, and find the problems in its development. This article mainly analyzes the basic form and internal logic of the e-commerce live broadcast sales model from the perspective of the supply chain. Relevant suggestions are proposed for its current development problems.
\end{abstract}

Keywords: E-commerce Live Broadcast; Web Live Broadcast; Supply Chain; Sales Model

\section{Preface}

In recent years, with the increasing cost of traditional e-commerce traffic and low Gmv conversion rate, the "e-commerce + live broadcast" mode with low cost and low threshold has ultra-high conversion rate, which has become a new growth point of e-commerce industry (Kong, 2020). In 2020, with the continuous fermentation of the "housing economy" of the epidemic situation, live broadcasting with goods has become an important means to promote economic recovery (Yao, 2020). Platforms/businesses, online/offline, stars/plain people and other parties have entered the market one after another, setting off a new wave of live broadcasting with goods.

Live broadcasting has become a new engine for the development of e-commerce, giving it new development momentum (Tang, 2020). Live broadcasting with goods has become a phenomenal new species. The flow realization of live broadcasting e-commerce has become the most deterministic and potential growth field of e-commerce industry. With the advent of $5 \mathrm{G}$ era, live broadcast will also become one of the standard configurations for retailers (Chai, 2020).

\section{The Basic Form of E-commerce Live Broadcast Mode from the Perspective of Supply Chain}

\subsection{Sales End}

The sales end is the main realizing position of the e-commerce live broadcast sales model, that is, the online celebrity anchors promote products through live broadcast on the e-commerce platform. This sales form has several major characteristics: one is the on-site, intuitive and comprehensive presentation of the product form; the second is the flow effect and opinion leader effect of the Internet celebrity anchor; the third is the network interaction of the sales process (Wang, 2020).

\subsection{Supply Side}

The supply side mainly refers to the manufacturer of the product. Manufacturers under the e-commerce live broadcast sales model can communicate with consumers directly through the anchor, without going through secondary distributors and agents to sell products to consumers. This shortens the distance between producers and consumers (Li, 2020). In addition, the manufacturer's product production can no longer design and 
manufacture products according to their own wishes, but needs to update products according to changes in consumer market demand and the opinions of live broadcasters.

\subsection{Consumer Side}

Consumers have become major fans of the network anchor. These consumers gather in the live broadcast room of the anchor through the network at the same time, and accept the same product point promotion at the same time. In the process of watching the live broadcast, the consumer's purchase behavior is affected by the anchor (Wang, 2020). According to the relevant investigation and research, at present, the consumers of ecommerce live broadcast mode are mostly women in the third and fourth tier cities, and most of them are "post90s" and "post-00s". The consumer group of e-commerce live broadcast sales mode is relatively fixed (Tang, 2020).

\subsection{Product End}

The product end of the e-commerce live sales mode has the following characteristics: first, the product price is lower; the product update and replacement speed are faster. The lower product price is due to the shortening of distance between producers and consumers, which reduces the price increase of multi ring middlemen; On the other hand, the host has the bargaining power with the producer relying on the consumer flow and strong trading ability brought by its huge fan group. For example, the products sold by Weiya, a famous anchor of Taobao, seem to have low price concessions (Yao, 2020). However, under the price strategy of a series of exclusive vouchers, step-by-step discounts, and time limited rush price at Taobao store, the price of single products can basically reach half of the normal price. This low-price strategy in the preferential way not only makes consumers enjoy the benefits, but also increases the sales volume of the businesses, thus realizing the win-win between consumers and businesses.

In addition, in the e-commerce live broadcast mode, in order to meet the diversified and personalized product needs of consumers, network anchors need to launch new products to consumers at a faster speed, which makes manufacturers speed up the development and update of new products according to the requirements of the anchor. For example, a certain Taobao head anchor's clothing products only broadcast 20 or 30 live every day, but almost every new product. Stop for a new day and fans may get bored. Therefore, in this kind of operation mode, the factory provides sample clothes and makes production and delivery according to the order after live broadcast which increases the pressure of the factory and the supply chain. On the other hand, it also promotes the improvement of the production and supply level of the factory and the supply chain.

\section{The Internal Logic of E-commerce Live Broadcast Sales Model from the Perspective of Supply Chain}

First, the e-commerce live sales mode meets the consumers' demand for price. Compared with the traditional e-commerce sales mode, e-commerce live broadcasting can further reduce the product price by reducing the intermediate link between producers and consumers and the bargaining power of network anchor, which greatly meets the price demand of consumers. Taking the live selling jade launched by a live broadcasting platform as an example, because it solved the shortcoming of false high product price caused by information asymmetry between businesses and consumers in the past, jade appeared in front of consumers at a lower price will rapidly attract many consumers. In addition, live selling jade also provides consumers with services such as selecting jade through the lens and bargaining for customers, which further lowers the product price. With the promotion of live selling jade to jade sales, businesses are more willing to take this way of small profit and quick turnover to achieve a win-win situation between consumers and themselves.

Secondly, the e-commerce live sales mode meets the needs of consumers for product brand and quality. Modern consumers pay more and more attention to the quality of products and have more trust in all kinds of brand products. The brand effect of e-commerce live sales mode is reflected in two aspects: first, the network anchor itself will check the quality of the products it promotes, and deliberately choose some brand products to promote; the network anchor has its own brand effect, and its popularity and reputation represent a brand. For example, when modern consumers mention lipstick brands, the first thing they think of is "Li Jiaqi", rather than a specific lipstick brand, which shows that "Li Jiaqi" has become the synonym of lipstick products to some extent.

Finally, the e-commerce live sales mode helps consumers solve the confusion of product selection. Traditional e-commerce sales focus on "people looking for goods" and consumers are faced with the screening of massive products. But because consumers don't know the product very well, there will inevitably be all kinds 
of hesitation and confusion in the choice. The anchor in the e-commerce live broadcast mode has the role of opinion leader. Through the intuitive product display, it can help consumers solve their choice confusion and stimulate consumers to make purchase decisions. According to the survey data of the iResearch on the reasons for users' live shopping, $58 \%$ of users are more intuitive and real because of the product display, $43 \%$ of them are more convenient because of the purchase link, and $37 \%$ of them are more competitive because of the preferential price. The iResearch consulting analysts believe that the comprehensiveness of the product display and the interaction between the buyer and the seller in the live broadcast process will prompt the consumers to solve their questions on the spot and facilitate the purchase.

\section{Problems in the Development of E-commerce Live Broadcast Sales Mode from the Perspective of Supply Chain}

\subsection{The Quality of the Goods Supplied Is Uneven}

At present, the e-commerce live broadcast sales mode is developing very rapidly, and the volume of live broadcast with goods is becoming larger and larger. Many online celebrities have started the live broadcast with goods mode. But in this process, the quality of supplied goods is also uneven. Some online celebrities simply pursue the shipment volume rather the quality of goods. The return rate is as high as $50 \%$, which is obviously too high compared with the return rate of $10 \% \sim 15 \%$ of traditional e-commerce. According to the survey of iResearch, only $27 \%$ of the respondents rarely cancel orders or return goods, and $26 \%$ of the respondents think that the return and exchange ratio of live broadcast sales will be higher than that of ordinary e-commerce.

\subsection{The Anchor Has Insufficient Management of All Links in the Supply Chain}

The supply chain behind e-commerce live sales is the foundation to support the Internet celebrity economy. Therefore, as the main body of front-end sales, the anchor should not only enhance its own influence but also manage the supply chain behind it. However, most of the current Internet celebrity anchors lack a basic understanding of supply chain management and just copy the traditional e-commerce supply chain. This obviously cannot meet the actual needs of the e-commerce live broadcast sales model. Insufficiency in supply chain management has also become an important factor restricting the future development of e-commerce live sales models.

\subsection{Lack of Brand Building Power}

The ability of selling goods of online red anchor under the mode of live broadcast sales of e-commerce is undoubtedly. As a marketing channel, however, it does not have the ability of brand shaping, which wastes a lot of marketing resources to a certain extent. In the increasingly fierce market environment, enterprises need sales volume as well as brand image. Therefore, the lack of awareness of brand building and the limited service provided by online red anchor to brand shaping in the supply chain restrict the promotion of the level of live marketing mode.

\section{Suggestions for the Future Development of E-commerce Live Broadcast Sales Model from the Perspective of Supply Chain}

\subsection{Clarify the Responsibilities of All Parties in the Supply Chain Regarding Product Returns}

The root cause of the problems of product quality and high return rate existing in the current e-commerce live broadcast sales mode lies in the unclear responsibility of all parties in the supply chain for product quality, so that no one takes the corresponding responsibility after the problem occurs, which further causes the lack of attention of all parties in the supply chain to product quality. Therefore, in the future, the relevant departments should further standardize the e-commerce live broadcast mode and clarify the responsibilities of all parties in the supply chain in terms of product quality so that the rights and interests of consumers can be protected and all parties in the supply chain can consciously control the product quality. 


\subsection{Improve the Level of Supply Chain Management}

As the foundation of the Internet celebrity economy, supply chain management must gradually rise to the center of the e-commerce live broadcast sales model. Especially when the current Internet celebrity sales model is gradually mature and perfect, the creation of anchors is easier than supply chain management. Therefore, for Internet celebrity anchors, more attention should be paid to the supply chain management behind them, and supply chain management can be carried out by forming a professional management team. At the same time, Internet celebrity anchors should also strengthen their learning and continuously improve their management capabilities. In addition, relevant departments should also strengthen supervision, provide guiding suggestions for supply chain management in the Internet celebrity economy, and continuously improve the overall supply chain management level under the e-commerce live sales model.

\subsection{Use Big Data Technology to Strengthen Brand Building}

Brand building is the key to enhance the core competitiveness of enterprises and products, but the current e-commerce live sales do not have this ability. The reason is the lack of in-depth mining of consumer demand because products cannot meet consumer demand in all aspects. Therefore, in the future, we should actively combine big data technology with e-commerce live broadcasting, and produce products that can fully meet the needs of consumers by analyzing the needs of consumers to gradually enhance the influence of products in the target groups and to achieve the effect of brand building. At the same time, with the help of big data to carry out more targeted marketing, the anchor can more accurately highlight the characteristics of the product when displaying the product to complete the brand positioning of the product in the hearts of consumers.

\section{Concluding Remarks}

As a new sales model, the stimulating and driving effect of e-commerce live sales on the consumer goods market is obvious. Analyzing its form from the perspective of supply chain, the explosion of the model demonstrates its own internal logic. Therefore, we should see the huge advantages and development potential of live e-commerce sales and continue to solve its problems in the future for the sustainability of this sales model.

\section{References}

1. Chai, S. (2020). Live Broadcast with Goods Gives New Momentum to Consumption in the Sinking Market. China's National Conditions and Power, 3: 10-14.

2. Kong, F. B. (2020). Live Broadcast with Goods Innovative Consumption Method. People's Daily.

3. Li, C. X. (2020). Exploring the Supply Chain Change of Garment Industry under the Net Red Economy. Modern Economic Information, 6: 368-373.

4. Tang, S. Q. (2020). Research on Live Sales Model of E-commerce in the Supply Chain Environment. China Press, 6: 46-49.

5. Wang, W. (2020). The Market Logic of Direct Broadcasting with Goods. China Bank Insurance Journal, 2020-04-24.

6. Yao, T. T. (2020). The "Cold" Thinking behind the "Hot" Live Broadcast with Goods. Qian XiNan Daily. 